\title{
Use of Social Media by the Undergraduate Medical Students: Students' Perception in Selected Medical Colleges of Bangladesh
}

\author{
Dr. Husneara Begum ${ }^{\prime}$, Professor Dr. AKM Asaduzzaman', Professor Dr. Humayun Kabir Talukder ${ }^{3}$, Dr. Tahmina Nargis ${ }^{4}$, \\ Dr. Kazi Khairul Alam ${ }^{5}$, Dr. Md. Asadullah ${ }^{6}$
}

\begin{abstract}
Introduction: This descriptive type of cross sectional study was carried out to explore the extent of use of social media by the undergraduate medical students and its consequences in medical education. This study was carried out in nine (Four public and five private) medical colleges all over Bangladesh during a period from July 2016-2017.

Objective: The study revealed that the use of social media by the undergraduate medical students and its effect on their lifestyle and medical education.

Methodology: Sample size was 673 medical students. Data was collected by self-administered semi-structured questionnaire from 673 respondents. Convenience sampling technique was adopted for data collection. For each variable frequency and percentages was calculated. There was also a part of in-depth interview for the respondents on the perception of use of Social media.

Results: Among the students $54.68 \%$ females \& $45.34 \%$ males, the mean age of the respondents was 20.76 years. Around $42.6 \%$ respondents were using Social media for $4-6$ years. The main use of social media by the respondents was Facebook $70.1 \%$, main devices was mobile phone $96.8 \%$. The main purpose of using the Social media for non-academic purposes such as, communicate with others $26.0 \%$, for chatting $51.3 \%$. Maxium duration $>4$ times / day up to $>6$ hours. Academic purpose $44.7 \%$ users using the SM every day. Six hundred forty six respondents agreed for negative effect of social media. $52.2 \%$ agreed that they used Social media during lecture class.
\end{abstract}

Conclusion: Most students had positive thoughts towards using social media. Students were using social media for almost nonprofessional reason. So, there is need to build up widespread awareness to use social media by medical students for professionalisms.

Key word: social media, undergraduate medical students, students perception ade to teach $3^{\text {rd }}$-year medical students on this important area under the 'Community Medicine' curriculum in Bangladesh.

\section{Introduction}

Social media is a form of electronic communication intended to create online communities where the users share information, ideas, personal messages, and other content. Social media sites are systems that allow the composition of general or semi-general profiles within a system with defined

\footnotetext{
1. Assistant professor, Department of, Community Medicine Enam Medical college, Savar, Dhaka

2. Professor \& Head, Department of Community Medicine Faridpur Diabetic Association Medical College, Faridpur.

3. Assistant Professor, Medical Education Centre for Medical Education (CME), Mohakhali, Dhaka.

4. Assistant Professor, Medical Education Centre for Medical Education (CME), Mohakhali, Dhaka.

5. Professor, Curriculum Development \& Evaluation, Centre for Medical Education (CME), Mohakhali, Dhaka.

6. Associate professor, Department of Orthopedics Enam Medical college, Savar, Dhaka
}

Address of correspondence: Dr. Husneara Begum

Assistant professor, Department of, Community Medicine

Enam Medical college, Savar, Dhaka

Email: sharafat.malek@gmail.com rules. Social media can be categorized into five groups: common projects (e.g., Wikipedia), blogs or micro blogs (e.g., Blogger, Twitter), content communities (e.g., YouTube), social network sites (e.g., Facebook) and virtual games or social worlds (e.g., Human Sim). ${ }^{1}$ Social media are not only shaping peoples' personal lives, they are also influencing professional environments. Within healthcare, recent estimates of social media usage by doctors has risen dramatically from $41 \%$ in 2010 to $90 \%$ in 2011 , while rates of use have been found to be above $90 \%$ for medical students. ${ }^{2}$ Medical education has grown beyond the boundaries of the classroom, and social media is seen as the bridge between informal and formal learning as it keeps students highly engaged with educational content outside the classroom. Although social media continue to grow, some educators find that they do not offer suitable modes of learning. Medical educators are encouraged to focus on the students in a way to minimize the gap between learners and educators. It will remain our responsibility as educators have to focus on the student, use SNSs at their fullest, and integrate them into traditional web-based management systems and into existing curriculum to the best benefit of the students. ${ }^{3}$ The evolution of social media has cut across all facets of society with its positive and negative impacts.

Bangladesh Journal of Medical Education 2018;9(1):11-15. (C) 2018 Begum et al., publisher and licensee Association for Medical Education. This is an Open Access article which permits unrestricted non-commercial use, provided the original work is properly cited. 
Social media has transformed and impacted on communication, learning, research and education in general. Among the vast variety of online tools which are available for communication, social networking sites (SNS) have become the most modern and attractive tools for connecting people throughout the world ${ }^{4}$. Advantages of social media apparently include fast and effective communication among people, dynamic social and collaborative environment and convenient access to information as well as promoting tool for businesses ${ }^{5}$.

Disadvantages of social media usage, however, encompass reduction of face-to-face interaction among people, sleep problems, anxiety and depression, concerns about privacy, fake identity, time consumption and most importantly addiction to social media that interferes with performing daily tasks ${ }^{6}$. Violation of confidentiality is one of the most concerning professional lapses in social media ${ }^{7}$. In addition, many researchers have argued that the attractiveness of the internet could lead to excessive use. Past research has described this phenomenon as Internet addiction ${ }^{8}$. On the other hand, Young (1998) ${ }^{9}$ argued that the Internet itself is not addictive, but highly interactive applications like online chatting can be addictive. Social networking sites have become a very important aspect in student's life ${ }^{10}$. In this paper, the researcher was answering to this question, what's the level of social networking sites used among Undergraduates Medical students in Bangladesh? What are the purposes of the use of social media uses by medical students? Find out students perceptions about social media. With the help of articles and journals that previous research notes, the researcher will reply to the question above.

\section{Objective}

To explore the use of social media by the undergraduate medical students and their perception.

\section{Methodology}

Descriptive type of cross sectional study. The study was conducted during the period of July 2016-june 2017. Data was collected from four public medical colleges and five private medical colleges. All the students of phase 1 to phase 4 MBBS course of the selected medical colleges during the period of data collection who were voluntarily participated in this study Sample size was 673 medical students of different medical colleges. Convenience sampling technique was used for this study.
Self -administered semi- structured written questionnaire. In-depth interview schedule. Pretesting of the data collection instrument was done among the first year MBBS students in non-selected medical colleges who comment on the functionality and comprehensibility of the questionnaire.

Data collection procedure: Data collection procedure followed conventional systematic random sample procedure. During collecting quantitative data students were informed that they might be contacted for further interviews if they were interested. With the aim of interviewing at least 20 students, they were later called for appointments.

Data presentation and analysis: Quantitative data: Questionnaire were edited after collection and manually coded and were undergone processing and analysis by using SPSS computer software according to the objective.

Qualitative data: Qualitative interviews from students were face to face interview and they were directly answered in mother language then were converted to english to analysis. These coded data were later used for generating results that directly answered the research questions.

\section{Results}

\section{Quantitative part}

The respondents of different government and nongovernment medical colleges. Among the total 673 respondents about 328 students $(48.73 \%)$ were government medical colleges and 345 students $(51.27 \%)$ were nongovernment medical colleges in phase 1 to phase 4 who were included as study sample. Majority $(52.7 \%)$ of the respondents were age group 21-25years. The mean age group of the respondents were 20.76 years. Among the respondents ( $n=673), 42.6 \%$ were using social media for $4-6$ years. About the most commonly usual time for the use of social media $(n=673)$ is $26.6 \%$ were in leisure time, $17.8 \%$ have no specific time, $12.9 \%$ when feel bore, $7.6 \%$ after going to bed. Per day number of times of use of social media 340 respondents were using $>4$ times /day. Respondents spending time with social media for academic purpose $(\mathrm{n}=673), 60.7 \%$ respondents were spending time up to 3 hours /week, 21\% up to 3-6 hours /week, 8.6\% up to 6-9 hours/week.

Table 1: Distribution of the respondents by their opinion about the positive effect of social media for medical students $(\mathrm{n}=673$ )

\begin{tabular}{|c|c|c|c|c|c|c|}
\hline Statements about the positive effect of social media & $\operatorname{SD} \mathbf{f}(\%)$ & $D \mathbf{f}(\%)$ & NAND $\mathbf{f}(\%)$ & Af $\mathbf{f}(\%)$ & SA $\mathbf{f}(\%)$ & Total \\
\hline $\begin{array}{l}\text { Social media has become an essential part in modern educational } \\
\text { life }\end{array}$ & $7(1.1)$ & $10(1.6)$ & $36(5.6)$ & $234(36.5)$ & $354(55.2)$ & 641 \\
\hline Social media lets me, public to others & $7(1.1)$ & $35(5.5)$ & $84(13.1)$ & $371(57.8)$ & $145(22.6)$ & 642 \\
\hline Social media gives me more information about my study & $8(1.3)$ & $29(4.5)$ & $96(15)$ & $322(50.3)$ & $185(28.9)$ & 640 \\
\hline I share class note with my friend via social media & $9(1.4)$ & $23(3.6)$ & $45(7)$ & $276(43.1)$ & $288(44.9)$ & 641 \\
\hline During exam social media helps me to take better preparation & $20(3.1)$ & $74(11.6)$ & $131(20.5)$ & $252(39.4)$ & $162(25.4)$ & 639 \\
\hline $\begin{array}{l}\text { Social media helps me to know more which sometimes is not } \\
\text { possible in real life }\end{array}$ & $11(1.7)$ & $40(6.2)$ & $70(10.9)$ & $348(54.3)$ & $172(26.8)$ & 641 \\
\hline
\end{tabular}

Bangladesh Journal of Medical Education 2018;9(1):11-15. 
Social media has become an essential part in modern educational life this statement was answered by 641 respondents, $55.2 \%$ were strongly agreed. Among the 642 respondents $22.6 \%$ were strongly agreed about the statement of Social media lets me public to others. Social media gives me more information about my study $28.9 \%$ were strongly agreed. $44.9 \%$ were strongly agreed with the statement $I$ share class note with my friend via social media. Six hundred thirty nine respondents were answered with the statement During exam social media helps me to take better preparation, $39.4 \%$ were agreed. Social media helps me to know more which sometimes is not possible in real life this statement were responded by 641 , out of them $54.3 \%$ were agreed, $26.8 \%$ strongly agreed .(Table- 1 ). $45.5 \%$ commonly utilize the social media for non-academic purpose,51.3\% respondents were commonly using for chatting. $38.3 \%$ respondents commonly gave opinion freely via comment and status posting. Social media has some negative effect on medical students $22 \%$ strongly agreed. During lecture class some students use social media 36.4\% were answered strongly agreed. Social media make medical students more addict on it this statements were answered by 643 respondents, out of them $28.3 \%$ were strongly agreed. Six hundred forty four respondents answered statement on using social media at late night then it make the students hangover at day time, $31.5 \%$ were strongly agreed with this statement. Another statement Social media influence the medical students on anti-social activity was answered by 644 respondents, $30.3 \%$ were disagreed with this. Social media waste many times this statement was strongly agreed by $29.4 \%$ among the 643 respondents .Have harmful effect/risk on use of social media this statement were strongly agreed by $18 \%$. 641 respondents answered the statement Unwanted information/picture may have negative psychological impact on the medical students with this statement $28.5 \%$ were strongly agreed.

Qualitative part: The researcher arranged in-depth interview schedule with 20 students of phase 2 in different medical colleges by personal communication. Description of the statement of one respondent in her own language:

"By using social media we can share lecture notes, if any topic I can't understand then I do connect by social media with my group or any friend, they / s/he has helped me. Different question answer we have to read from different books. Not all the books are brought to class. So we scan the books pages and save it in our mobile and share it with friends. Most of the facebook group is using just information share, such as class schedule change, ward schedule change, etc. So we are so much active in net. I am a female, so many harassment by suing social media, such as if I upload my picture then it collect, and open a fake ID. Then I have depress. It has done maximum female student. They can't do anything but feel mentally upset". (A female 3 rd year medical student).

\section{Discussion}

In the last ten years, the online world has changed dramatically due to the prodigious expansion of social media and their users. Social media consist of a set of websites and applications that allow the users to share contents, ideas, feelings, experience and communicate with large number of users $^{11}$. Social networks have a significant impact on students' literacy and used as tools for aiding students' academic achievement. Educators and researchers have found that networks are becoming rapidly used in medical education .The emergence of social network tools revealed value in the medical learning practice ${ }^{12} .673$ undergraduate medical students, $48.7 \%$ were government \& $51.2 \%$ were non-government in different phases of medical colleges were participated in this cross-sectional survey consisted of female $54.68 \%$ and $45.34 \%$ male. A cross sectional survey was done on the medical college students of MVJ medical college \& research hospital over a period of 3 months consisting of 408 students . $274(67.2 \%)$ were females and $174(32.8 \%)$ were males ${ }^{13}$. In many studies the age group between $18-25$ years $(20.71 \text { years mean age })^{14}$. The dominant age group of this study was 21-25 years with a mean age group 20.76 years. The Social Media was established in 2004 by Mark Zuckerberg ${ }^{11}, 42.6 \%$ medical students using the social media since 4-6 years. About the most commonly usual time of social media $(n=673)$ is $26.6 \%$ were in leisure time, $17.8 \%$ have no specific time, $12.9 \%$ when feel bore, $7.6 \%$ after going to bed. Per day number of times of use of social media 340 respondents were using $>4$ times /day. The long duration of daily online network usage (1-2 hours; $68.5 \%$ ) might be due to electric devices that allow for easy and friendly access, thereby allowing medical students to use social networks more often even in class ${ }^{15}$. The most using is during study (78.9\%) because most of users study alone and tend to use SNs as break or when they feel dullness ${ }^{16}$. Respondents spending time with social media for academic purpose $(\mathrm{n}=673), 60.7 \%$ respondents were spending time up to 3 hours /week. In Pakistan the findings for main purpose of the SM using Contacting friends(40.8\%), Having fan $(40 \%)$, Communicating with friends $(34.6 \%)$ among the physiotherapy students ${ }^{14}$. The time spent on social media reported in Iraqi students 2 hours per day but some more than 6 hours $^{11}$. Further observation may be needed to find association between the frequency of time spending in SM and students' academic performance.

Every new technology has both positive and negative effects. In Table -1 addressed the positive effects of SM for medical students. The researcher found that most of the respondents were agreed and strongly agreed with the positive effect( $\mathrm{n}=$ 642).According to some reports Facebook is used by students instinctively so as to support their academic as well as social purposes; on the contrary, majority of the evidence revealed that Facebook is used by students mainly for social connectivity. Despite this, it is being recognized as an elearning platform ${ }^{17} .45 .5 \%$ commonly utilize the social media for non-academic purpose, $42.4 \%$ respondents sometimes to find old friends which they have lost.59.2\% commonly to know news of friends. $51.3 \%$ respondents were commonly used for chatting. $38.3 \%$ respondents were commonly gave opinion freely via comment and status posting. This result is parallel with students used SNSs mainly to chat with friends $(94 \%, 59 / 63)$, for medical education purposes $(67 \%, 42 / 63)$,

Bangladesh Journal of Medical Education 2018;9(1):11-15. 
to share videos $(62 \%, 39 / 63)$, to post opinions $(49 \%, 31 / 63)$, to take surveys $(11 \%, 7 / 63)$, and to play games $(6 \%, 4 / 63)^{3}$. The researcher did not compare males and females respondents opinions for nonacademic use of SNSs. However, with the various amount of social networking sites further research need to consider these sites for educational values, and its effects on the medical learning. When the respondents were asked about the negative effect of SM use on medical students more than $45 \%$ respondents were agreed with this. negative effect of social media such as addiction on it, use during lecture class, wastage many times, unwanted information or picture may have negative psychological impact, by using late night it may hangover daytime during class. The researcher observations was same as Memon A,R, Azim M,E, \& Kiyani M,M, according to them Psychiatrists introduced the term Facebook addiction because it damages the sleeping habits and health's and abilities to interact and interest to studies. $91 \%$ users agree about negative effect of using the social networks on all students' academic performance and $87.9 \%$ users agree about negative effect of using the social networks on concentrating during academic activities, by compare with study in Nigeria in $2011^{16}$. In this study, the researcher invited some suggestions to overcome the negative effect of SM. 35.3\% respondents were strongly agreed for specific law make by the government, There are several studies already recommend the ethical guidance for the medical students to using the SNSs . Creating such a website would need the presence of guidelines for posting educational materials, including ethical terms (confidentiality and respect of patient rights). Many countries have released policies regarding the professional use of SM, such as the American Medical Association policy ${ }^{18}$.

\section{Conclusion}

The research paper is relevant as preliminary observing the students perceptions about the social media for academic and non-academic purposes. In this study the researcher observed and found that the Bangladeshi medical students were using social media technology and their perception about the modern media. The researcher discovered that the medical students were using this media mostly to entertainment with their friends not only to communicate with each other's. They were also using for many academic information sharing, group discussion with friends and peers. Medical students have positive thoughts towards using this media. They are more benefited by using this media. They thought that this media make them more advanced in this modern era. Social media have changed human life as well as educational life and students are more attracted to this innovative technology.

\section{Recommendations}

The prevalence of use of social media is high in medical students and it increases day by day. Now a days social media connect the whole world .So in medical education use of social media have to be improved.

1. Initiative to be taken for developing widespread awareness to use of social media by medical students for professionalism.
2. Teachers to think for the utilizing of social media for academic purpose.

3. There needs to be proper institutional guideline for using the social media by the undergraduate medical students.

\section{References}

1. Çelikden S G, Eren S, Aydenizöz D,\& Avc K, (2015), "Assessment of medical students' attitudes on social media use in medicine: a cross-sectional study."BMC Medical Education201515:18

2. Daniel R. George, Liza S. Rovniak, Jennifer L.Kraschnewski,(2013),"Dangers and opportunities for social media in medicine." ClinObstet Gynecol. 56(3): 10.1097/GRF.0b013e318297dc38

3. El Bialy S, JalaliA, (2015), "Go Where the Students Are: A Comparison of the Use of Social Networking Sites Between Medical Students and Medical Educators." Vol 1, No 2 ,Jul-Dec

4. Aghazamani.A;(2010)."How do University Students Spend Their Time on Facebook?"An Exploratory Study.Journal of American Science, 6, 730-735.

5. Guedes E, Nardi AE, Guimarães FM, Machado S, King AL,(2016),"Social networking, a new online addiction: a review of Facebook and other addiction disorders. Medical Express 2016

6. Griffiths MD,(2013), "Social Networking Addiction: EmergingThemes and Issues." J Addict Res Ther; 4:e118.

7. Elizabeth A. Kitsis,Felise B. Milan, Hillel W. Cohen, Myers D , Herron P,McEvoy M, Weingarten J, Martha S. Grayson,(2016), "Who's misbehaving? Perceptions of unprofessional social media use by medical students and faculty." BMC Medical Education .BMC series open, inclusive and trusted201616:67

8. Grifiths, M. (2010), "Internet abuse and internet addiction in the workplace." The Journal Of Workplace Learning, 22(7), 463-472.

9. Young, \& Kimberly, S, (1998),"Internet addiction: The emergence of a new clinical disorder." Cyber Psychology \& Behavior Journal., 1(3), 237-244.

10. Lenhart, A., Madden, M., \& Hitlin, P(2005), “Teens and technology: Youth are leading the transition to a fully wired and mobile nation”. Pew Internet And American Life Project

11. AlahmarT.A;,.(2016), "The impact of social media on the academic performance of second year medical students at College of Medicine, University of Babylon, Iraq". College of Medicine, University of Babylon, Iraq

12. Alhaj,A, Altalyb; Banafi.H,N; (2015), "The Impact of Social Networks on EFL 2015MedicalStudents' AcademicPerformanceatJazanUniversity."dobasi77@ gmail.com,e_nhb@yahoo.com. 
13. Madaiah M, Seshaiyengar T,C, Suresh P, Munipapanna S, \&Sonnappa D S.(2016), "Study toassess the effects of social networking sites on medical college students." Int J Community Med Public Health.; 3(5): 1204-1208

14. Memon A,R, Azim M,E, Kiyani M,M, Ameer MR, Ali SM, Malik A,N, (2014), "Perceptions, Practices, and Use of Facebook: A Cross-sectional Survey on Physiotherapy Students in Pakistan." J Community Med Health Educ 4:327.

15. Tanawattanacharoen S,Wongkietkachorn A, (2013), "Medical students' online network abuse"South-East Asian Journal of Medical Education Vol. 7 no. 1,

16. Elhuda, A,D\& Dimetry D. A,(2014) ,"The Impact of Facebook and Others Social Networks Usage on Academic Performance and Social Life among Medical Students at Khartoum University." International journal of scientific \& technology research volume 3, issue 5, Issn 2277-8616
17. Irwin C, Ball L, Desbrow B, Leveritt M ,(2012), "Students' perceptions of using Facebook as an interactive learning resource at university." Australasian Journal of Educational Technology 28: 1221-1232.

18. Alsuraihi, A. K;Almaqati, A S;Abughanim. S, A;Jastaniah A,N, (2016), "Use of social media in education among medical students in Saudi Arabia". Korean J Med Educ 2016; 28(4): 343-354. Published online: December 1,

1. MMEd,12th Batch Session:2015-16

2. Prof. \& Head of the department of Community Medicine, Diabetic Association Medical College, Faridpur.

3. Professor, Curriculum Development and Evaluation, Center for Medical Education

4. Assistant Professor, CME

5. Assistant Professor, CME

6. Associate professor, Orthopedics department, Enam Medical college,

Bangladesh Journal of Medical Education 2018;9(1):11-15. 